\title{
Project-oriented Development and Practice of the Machinery Manufacturing Technology Course
}

\author{
https://doi.org/10.3991/ijet.v13i05.8354 \\ Xiaomian Li, Tiejun $\mathrm{Wu}^{\left({ }^{\square}\right)}$ \\ Dongguan Polytechnic, Dongguan, China \\ wtj1980@126.com
}

\begin{abstract}
The traditional teaching of machinery manufacturing technology considers typical parts, such as the axial and box - the teaching carriers and focuses on explaining theoretical knowledge and cultivating the determining process capabilities but does not integrate the processability of the product structure, processing, measurement, or assembly of mechanical parts. This type of teaching is dissociated with the actual production process of mechanical products and does not meet the requirement for students to solve actual problems by using mechanical manufacturing technology. The course development concept of working process systematization was investigated, and the main work positions, typical work tasks, corresponding professional ability requirements of mechanical and equipment enterprises, and course objectives were analyzed. Three learning projects with progressive difficulty and six interrelated tasks were designed on the basis of creating typical mechanical products. Teaching was conducted according to an action-oriented, six-step method to realize the teaching mode of "doing in learning, learning in doing." The results indicate that students and enterprises recognize the teaching design proposed in this study. The interest of students in learning was evidently increased, and their ability to solve practical production problems through a comprehensive application of professional knowledge was enhanced.
\end{abstract}

Keywords-Machinery manufacturing technology, project-oriented, typical products, teaching

\section{Introduction}

Mechanical manufacturing technology is the core course for developing the professional ability to cultivate high-quality technical talent in mechanical manufacturing and automation [1]. The general concepts of developing the course are as follows: (1) regard occupation ability as the direction, enterprise post demand survey as the basis, and occupation qualification as the reference standard; (2) adopt the integrated teaching mode oriented through work process, combined teaching, and working processes; and (3) develop systematic courses combined with production processes.

The corresponding positions and post groups for mechanical manufacturing and automation professionals were determined, in which enterprise engineering technical 
personnel, high vocational education experts, and professional teachers implemented typical task analysis. These positions and groups were determined on the basis of investigating the talent demands for electromechanical products and equipment manufacturing enterprises in the Pearl River Delta Region and a follow-up survey of the graduates (shown in Table 1).

Table 1. Position groups and typical tasks in mechanical manufacturing and automation major

\begin{tabular}{|c|c|c|}
\hline $\begin{array}{l}\text { Position } \\
\text { groups }\end{array}$ & $\begin{array}{c}\text { Employment } \\
\text { position }\end{array}$ & Description of typical work tasks \\
\hline $\begin{array}{l}\text { Operation } \\
\text { position }\end{array}$ & $\begin{array}{l}\text { Machine tool } \\
\text { operators }\end{array}$ & $\begin{array}{l}\text { Operation of general machining equipment, such as turning-lathe, } \\
\text { milling, and drilling machine } \\
\text { Bench workers, assembler, toolmaker } \\
\text { Computer numerical control programming and operation } \\
\text { Non-traditional machine tool operation } \\
\text { Maintenance and commissioning of machining equipment }\end{array}$ \\
\hline \multirow[t]{2}{*}{$\begin{array}{l}\text { Technology } \\
\text { positions }\end{array}$} & Technologist & $\begin{array}{l}\text { Process plan and technological process designs of mechanical parts } \\
\text { Design and implementation of process equipment plan } \\
\text { Formulation of the working scope and operating procedure of machin- } \\
\text { ing equipment } \\
\text { Implementation of field process for mechanical products } \\
\text { Analysis of technical quality accident in workshop } \\
\text { Maintenance and commissioning of machining equipment }\end{array}$ \\
\hline & $\begin{array}{l}\text { Workshop quality } \\
\text { inspector }\end{array}$ & $\begin{array}{l}\text { Quality inspection of mechanical parts } \\
\text { Construction of product quality assurance system and standards } \\
\text { Analysis of technical quality accidents in workshop and suggestions } \\
\text { for improvement }\end{array}$ \\
\hline \multirow{2}{*}{$\begin{array}{l}\text { Management } \\
\text { positions }\end{array}$} & $\begin{array}{l}\text { Workshop pro- } \\
\text { duction dispatcher }\end{array}$ & $\begin{array}{l}\text { Process arrangement and technological process design in mechanical } \\
\text { product manufacturing site } \\
\text { Implementation of working range and operating rules of machining } \\
\text { equipment } \\
\text { Production management of machining workshop } \\
\text { Determination of man-hour and quota for mechanical parts }\end{array}$ \\
\hline & $\begin{array}{l}\text { Material pro- } \\
\text { curement and } \\
\text { manager }\end{array}$ & $\begin{array}{l}\text { Supplier evaluation and management } \\
\text { Implementation of procurement plan and preparation } \\
\text { In-and-out-of-storage management } \\
\text { Disposal of unqualified materials } \\
\text { Disposal of backlog materials }\end{array}$ \\
\hline Sales position & $\begin{array}{l}\text { Mechanical and } \\
\text { electrical products } \\
\text { salesman }\end{array}$ & $\begin{array}{l}\text { Understanding user requirements } \\
\text { Provide solutions to customers } \\
\text { Business negotiation } \\
\text { Customer relation management } \\
\text { Complaint Handling } \\
\text { Track sample information }\end{array}$ \\
\hline Service position & $\begin{array}{l}\text { After-sales ser- } \\
\text { vice personnel }\end{array}$ & $\begin{array}{l}\text { After-sales technical services } \\
\text { Formulation of after-sales service clauses } \\
\text { Formulation of fault-handling process } \\
\text { Customer demand and product improvement training }\end{array}$ \\
\hline
\end{tabular}

The mechanical manufacturing technology course was designed to satisfy the requirements of machining, quality inspection, and assembly of mechanical parts based on analyzing typical professional tasks of machine tool operators, technologists, and 
workshop quality inspectors. These professional tasks include reading and analyzing the parts of a drawing, technological procedure programming of mechanical parts, designing and implementing process equipment plans, application scopes, and operating rules of machining equipment, implementing the field process of mechanical products, and analyzing workshop technical quality accidents.

\section{State of art}

The mechanical manufacturing technology course, as a core course of the machinery manufacturing and automation specialty group, has been investigated and reformed by numerous high vocational colleges in project-oriented teaching. For example, Jiang (2015) designed seven projects, including cylindrical processing parts, planar mill, and spindle box parts machining [2]. Yang (2016) created five projects, including plate machining and processing of sleeve and shell parts [3]. Furthermore, $\mathrm{Ju}$ and $\mathrm{Xu}$ (2009) planned five projects, including rotor processing, end-cover processing, and root flowmeter assembly [4]. Sun (2017) designed three projects, including shaft part processing, shaft sleeve parts, and fork brackets [5]. Yan and Xiao (2011) built five typical projects, including shaft part processing, box parts processing, cylindrical gear processing, and assembly process [6].

The aforementioned studies focused on the course design of project-oriented teaching. A general-purpose machine tool metal-cutting method categorized metal cutting as the method of turning, milling, and grinding and designed learning projects in accordance with the grade of processing the economic precision of each processing method [1-3]. Sun and Yang considered the typical mechanical parts as the basis for sorting and classified these parts into the shaft, plate, and box [5-6]. Moreover, the learning project was designed in accordance with the complexity of parts.

However, implementing the course excessively reinforced skills training [1-6]. The practice was merely repetitive, thereby lacking the element of training, and students did not maintain their interest in learning. The work task designed by $\mathrm{Ju}$ and $\mathrm{Xu}$ was extremely difficult and unrealistic and did not match with the training in schools. Moreover, realizing the goal of creating a teaching design was difficult given the high cost of teaching.

In summary, three learning projects - that is, jack, special fixture, and stamping die with the complete mechanical product - were designed into this study as the project carrier by considering product technology as the breakthrough point and realizing an effective link between projects based on the engineering properties of the parts. The interest of students in learning was stimulated and maintained through the integrality and practicability of the mechanical products to realize the double helix progression of theoretical knowledge and professional ability by implementing a multidimensional increase of the project [7]. 


\section{$3 \quad$ Learning project design based on typical products}

Teaching content was selected with regard to the national professional standards for lathe workers, mill workers, millers, grinders, and assemblers as the references according to the knowledge, ability, and quality required for developing enterprises and the demands for completing professional practice activities. The principles of cognitive learning and professional growth of students and the learning content suggested that learning points should be integrated into the working process from simple to complex and from single to comprehensive; this course aimed at realizing consistency of teaching and working processes and reflecting program objectives to cultivate the ability of students in machining and determining processes, comprehensively applying professional knowledge, and solving practical problems in production [810].

In accordance with the characteristics of the product machining method, three learning projects - namely, jack assembly, special fixture design and assembly, and stamping die drawing and assembling - were designed into the learning project combined with the actual situation of higher vocational students and practical training conditions of Dongguan Vocational and Technical College. Fig.1 illustrates that two tasks with varying and progressive degrees of difficulty were designed into each project [11]. The six tasks are closely combined with engineering practice, covered the teaching tasks of the machinery manufacturing technology course, and constructed a complete teaching system. Each project included implementing the process preparation and machining task of typical products as the main line and realized the doublespiral progression of theoretical knowledge and practical ability by increasing the degree of complexity of parts from simple to complex (Fig.2) [12-14].

Typical products in a task were designed by considering three factors as follows:

(1) Engineering uses the value and integrality of the teaching content. The products processed by the students, such as a simple jack and jig, must have a certain practical value, as depicted in Fig.1.

(2) The connection between work tasks can be achieved.

In many documents, typical mechanical parts are also used as carriers for designing projects or work tasks. However, these work results do not belong to the same mechanical product, and the work tasks lack organic connections.

The task results of each project in this course were assembled into mechanical products, as demonstrated in Fig.2. This kind of part processing is close to the actual production process of enterprise products and can stimulate the interest of students in effectively learning through the practice of teaching. Moreover, students have a strong interest in learning throughout the course. 

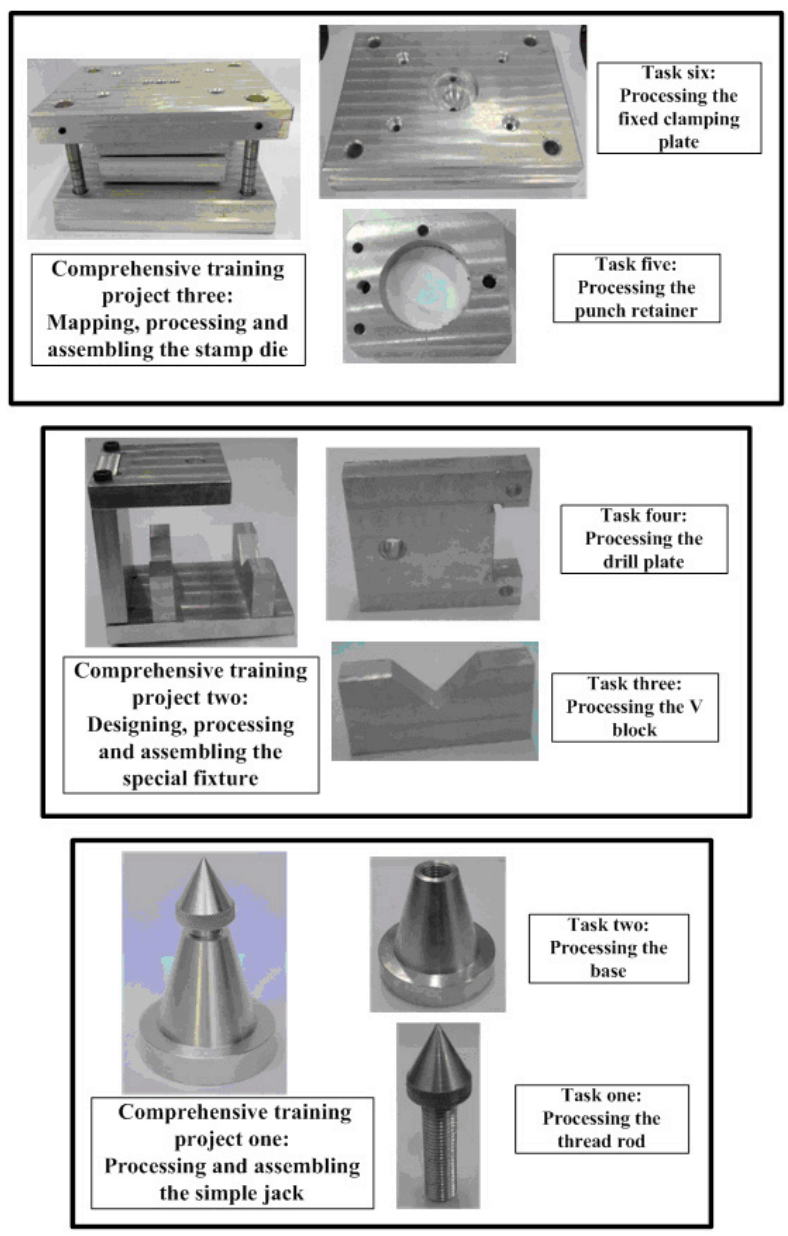

Fig. 1. Learning project design of machinery manufacturing technology

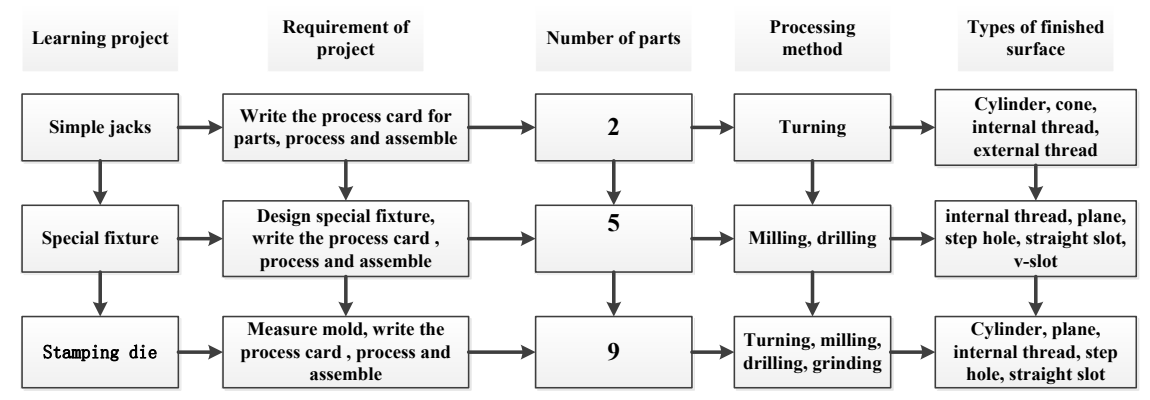

Fig. 2. Schematic of the increasing difficulty in a learning project in the machinery manufacturing technology course 
(3) Typical mechanical products, as the carrier of knowledge and the goal of skill development, must carry knowledge with inherent logic and incremental skill goals.

A simple jack, which was the carrier in learning project 1 required students to master the knowledge of craft route planning, cutter selection, and machining processing technological procedures. In addition, this part enabled students to write the process card for parts, process thread rods and foundations on a turning-lathe, and assemble the parts. Jig, which was the carrier in learning project 2, required students to grasp the knowledge points of a process diagram and working allowance and design a set of drilling tools by applying the knowledge point of a six-point positioning principle and positioning error. In addition, jig allowed students to draw parts, write process cards for parts, process all parts on turning-lathe and milling machine according to the process card, and assemble the parts. Stamping die, which was the carrier in learning project 3, required students to grasp the knowledge points of assembly precision and method, analyze and determine the tolerance and surface roughness of the main surface of each part according to dimensional tolerance and fit, draw part and assembly illustrations, process all parts on turning-lathe, milling machine, and grinder, and assemble the parts.

\section{$4 \quad$ Teaching example and effect}

Appropriate teaching content was selected based on the requirements of the theoretical knowledge, position ability, and professional quality after discussion by professional teachers, enterprise experts, and engineers. The discussion was in accordance with the course development concept regarding typical products as the carrier and implementing process preparation and machining of products as the mainline given the process and specifications of product machining. Experts, engineers, and business managers were invited to design study projects, work assignments, and professional competencies for students. Teachers with "double certificates" and frontline technical experts organized the teaching and practice activities.

The machinery manufacturing technology course group formulated the learning goal, teaching implementation plan, required equipment objects and tools, teaching emphases, teaching documents (Fig.3), and assessment and evaluation criteria for each task. Course teaching was implemented through a six-step teaching method that included task consultation, task decision, program planning, task implementation, task checking, and result evaluation $[15,16]$.

The teacher conducted the course teaching according to the six-step teaching method after designing the work tasks in the teaching plan and introducing the tasks step by step. The intended goal was only achieved by implementing the teaching methodically. The implementation of tasks in the machinery manufacturing technology course is described below: 


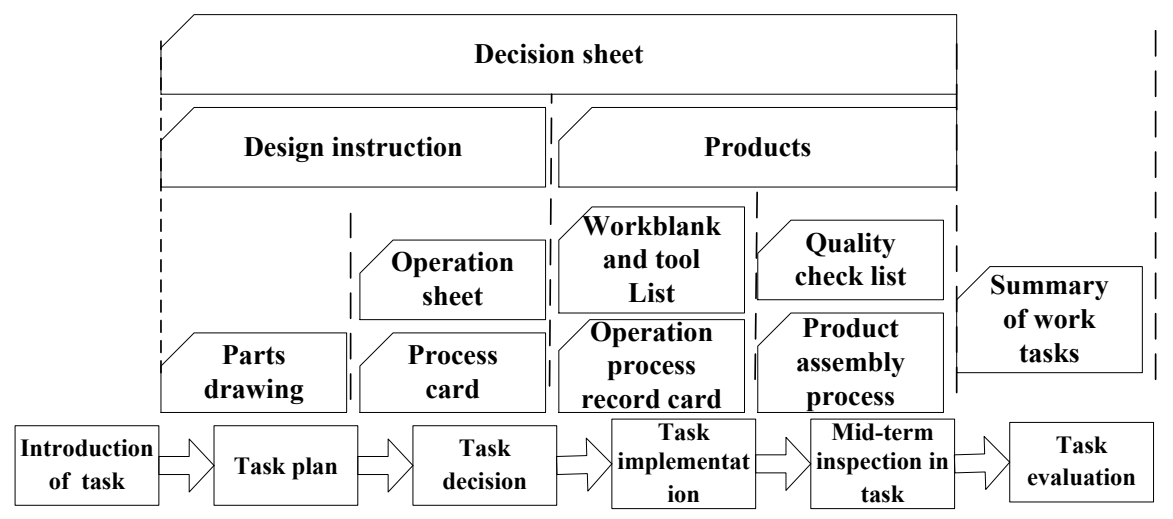

Fig. 3. Documents filled in by students over the course of the six-step teaching

\subsection{Introduction of tasks (consultation)}

First, the teacher presented a series of questions to the students according to their knowledge and ability at the present stage by displaying the physical objects of the mechanical products and CAD diagram (Fig.4 displays the physical and part drawings of the parts to be processed, such as the baseplate of drilling jig fixture, in task 5). The surfaces of the workpiece that can be machined were determined according to the procedure. The process of machining the workpiece was identified. Appropriate machine tools and process equipment were required and determining the clamping scheme of the workpiece was performed, On the one hand, the teacher could determine the students' grasp of knowledge and skill based on their answers. On the other hand, the teacher could introduce new theoretical knowledge to be mastered in real time; thus, the students could clearly understand their learning goals and stimulate their interest in learning.

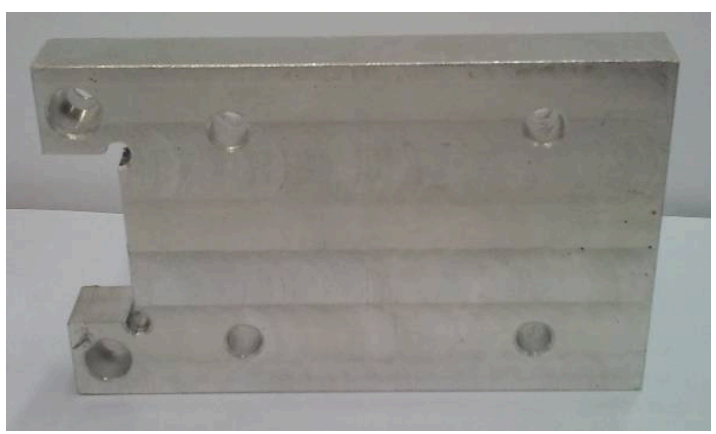

a) Physical drawing

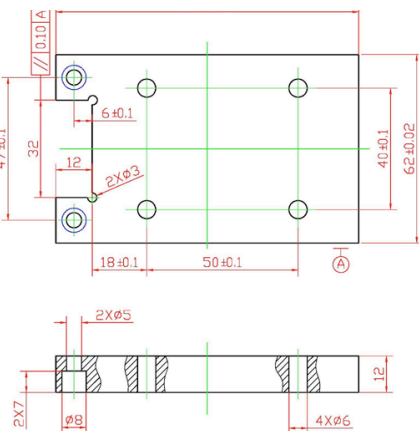

b) Part drawing

Fig. 4. The baseplate 


\subsection{Task plan}

Students were required to plan the work tasks in groups by analyzing the workpiece and the teacher's explanation in terms of the new knowledge. In the first two or three tasks of the course, the students were randomly divided into groups or a through a game because the teacher had no knowledge of their comprehensive abilities in the class. In the later tasks, the teacher identified the learning abilities of all the students through examination of the technological procedures in the classroom and the accuracy of the parts. Afterward, team leaders and members were designated. The teacher arranged the task books for the students. Students read the content of the task books, analyzed the theoretical knowledge involved in the task to find relevant information, and then determined the work plan. Each group leader divided the task within the group and filled in the content of the design instructions.

\subsection{Task decision}

Each working group began to draw up the process route in accordance with the technological procedure implementation process of parts machining and compiled the engineering cards, process cards, and design instructions. The task was independently conducted from this link by the learning group. The whole task was completed as a team given the cooperation of the team members. The teacher transformed from a teacher of knowledge to a consultant and mentor of student behavior and guided students in performing information inquiry, task decisions, and task completion through autonomous, cooperative, and inquiry learning in interaction with students to realize "learning in the working process and working in the learning process." Students gained experience by independently handling problems in real jobs; this knowledge was invaluable for their future careers. This approach was also an important link for students to gain experience in action-oriented teaching.

\subsection{Mid-term inspection in task}

This link was designed to prevent the students from suffering physical injury due to errors in the process documents. The general-purpose machine tools used by students were devised without special safety guards because of the machining of parts in the mechanical manufacturing technology course. Students were vulnerable to injury when the machining parameters or clamping schemes identified by the students were unreasonable. In this link, the students first found errors through group checks. The teacher then guided the students to analyze the causes of the problem and correct the errors in time through group Q\&A. Each team corrected technological procedures based on mutual and teachers' checks and filled in the Q\&A form and tool list.

\subsection{Task implementation}

In this part, the task was aimed at guaranteeing the operation specification and avoiding personal injury of the students considering the risk of students in operating 
the machine tools. Students were required to work in groups to produce parts that satisfied the precision requirements within a specified time. This method is slightly different from the requirements of enterprises. The vast majority of plant operators are skilled workers. Students can only operate machine tools skillfully after completing the course. Therefore, safety education was conducted through operation specification questions before each part was processed. Each working group had a safety supervisor whose primary responsibility was to record the steps and processing times of operating the machine tool conducted by the team members. The safety supervisor had the right to order the student to stop the machine as prescribed and reported to the teacher when the safety supervisor found the operation of the machine tool was unreasonable or incorrect to solve the problem in time. The task implementation of this course was conducted in the practical training center of the school. Three teachers were present on the spot. The first teacher inspected and supervised the operation at the site. The second teacher helped the students remove the malfunction of machine tools and process equipment, assisted the students in analyzing machining accuracy and quality, and recorded the typical problems in each task. The third teacher managed the work blank, cutter, and measurements.

\subsection{Task evaluation}

The parts were exchanged with the parts processed by another group for checking when the working group completed the processing of the parts and implemented selfinspection. The checklists of the parts were filled in and handed over to the teachers for inspection.

This link was mainly a diversified evaluation of the work results, and the main body of the evaluation was the teachers and students. The evaluation indexes included the process norm, completion results, completion time, labor division among the group members, and team collaboration. First, the leader of the working group introduced the labor division to the group, demonstrated the work results (parts, process sheet, operation sheet, and design instruction), described the team's work process, problems, solutions, and gains, and conducted self-evaluation. Other working groups asked questions regarding techniques and methods related to implementing the tasks and evaluated according to the answers and achievements obtained. Teachers also fed the results back to students in each group, affirmed their achievements, presented their shortcomings, and motivated their thinking to be objective and realistic. The best results were selected by mutual and teacher's evaluation after the presentation.

\section{Conclusions}

Three learning projects with increasing difficulty were designed in this study based on the actual products of enterprises. These projects were simulated according to the cognitive learning and professional growth laws of students. The design of these projects was guided by the knowledge, ability, and quality required by the development of enterprises and the completion of practical vocational activities. The teaching or- 
ganization and implementation based on the "six-step teaching method" were explained in detail. These technologies played a positive role in processing mold design and manufacturing. This study introduced the computer-aided teaching and developing a process of mold design, model flow analysis, and simulation processing through the existing software by considering the injection mold of a desk lamp cover as an example. The teaching implementation effect was evaluated by questionnaires, and the following conclusions could be drawn:

(1) The required theoretical knowledge was integrated into the working process to achieve consistency between the teaching and working processes. The practice skills, practical engineering problem analysis and solving ability, and creative ability of the students improved. The sense of teamwork and production safety was prominent.

(2) The interest of students in learning was maintained throughout the course by studying and practicing three mechanical products with increasing difficulty.

(3) The teaching method satisfied the requirements for the comprehensive ability of students to solve practical problems in the production of machinery through mechanical manufacturing technology.

\section{Acknowledgment}

This work was supported in part by the Educational Science Planning Group of Guangdong Province (2013JK307) and Education Project of Dongguan Polytechinicn (JGXM2015013) .

\section{$7 \quad$ References}

[1] X.H. Jiang, Z.H. Wang, W. Qian. Engineering Case Oriented Reform of Mechanical Manufacturing Technology Course. The Guide of Science and Education, 2017, vol.31 (33), pp.140-142.

[2] S.Q. Jiang. Improving the Teaching Connotation of "Mechanical Manufacturing Technology" Course with Practice as the Carrier. Communication of Vocational Education, 2015,vol.5 (18), pp.7-9.

[3] Yang Anyuan. Application of Project Teaching Method in the Course of Mechanical Manufacturing Technology . Journal of Kaifeng University, 2016, vol.30 (4), pp.72-73.

[4] Jv Jiabin, Xu Guangchi. Development and Practice of Learning Field of "Product process Identification and compilation". Vocational Technology, 2009, vol.106 (06), pp.51.

[5] Sun Hui. Discussion on Project-oriented Teaching Mode of the Course of Mechanical Manufacturing Technology. China Metallurgical Education, 2017, vol.181 (4), pp.10-11.

[6] Yan Wenping, Xiao Yahui. Project-oriented Teaching Design of Mechanical Manufacturing Technology Course in Higher Vocational Education. Education and Vocation, 2011, (29), pp.142-143.

[7] T. J. Wu, J. F. Yu, L. T. Liu and D. L. Zuo. On the Performance Evaluation Method of Mechanical Manufacturing Technology Course Based on AHP and TOPSIS. Revista de la Facultad de Ingeniería U.C.V., 2017, vol.32 (1), pp.264-273. 
[8] T. J. Wu, L.G. Li, J. F. Yu, H.Y. Zhang, W. W. Zhang. Research and practice on the practical course of Mechanical Manufacturing Technology based on typical products. Vocational \& Technical Education Forum, 2013, (21), pp. 78-82.

[9] B.P. Zhao. Application of Project-oriented Teaching method in the course of Mechanical Manufacturing Technology. Shandong Industrial Technology, 2017, (11), pp.232.

[10] Y. Sun. Exploration on the Project-oriented Teaching Reform of Mechanical Manufacturing Technology in Vocational Colleges. Journal of Baotou Vocational \& Technical College, 2017, vol.16 (4), pp.85-88.

[11] T. J. Wu, Z. Chen and X. M. Li. Design and implementation of the course of machinery manufacturing technology based on project-oriented teaching. Journal of Chemical and Pharmaceutical Research, 2015, vol.7 (3), pp.543-549.

[12] H.J. Wang, J.L. Zhong, Z.H. Liu. Teaching Evaluation of Basic Course Design of Mechanical Manufacturing Technology based on OBE. Education Teaching Forum, 2017, vol.9 (51), pp.230-231.

[13] F.Z. Liang, M.H. Meng, H.Y. Liu. Exploration on the Teaching Reform of Mechanical Manufacturing Technology course guided by Engineering Awareness. China Educational Technology \& Equipment, 2013, vol.33, pp.105-106.

[14] J.Q. Lin. Construction and Practice of the Secondary Vocational Curriculum System based on the Cooperation between Schools and Enterprises-Taking the specialty of the secondary vocational machinery manufacturing technology as an example. Journal of Fujian Institute of Education, 2017, (6), pp.120-122.

[15] Y.J. Du. Research and Discussion on Practice Education Reform on Logistics Equipment and Technology for Higher Vocational School. Vocational \& Technical Education Forum, 2017, (24), pp.88-92.

[16] F. Hou. Discussing on Educational Reform for Image Processing Course. Journal of The Chinese Society of Education, 2017, (s1), pp.86-90.

\section{Authors}

Xiaomian Li is a lecturer in Mechanical and Electronic Engineering Department, Dongguan Polytechnic, Dongguan 523808, China (email: 259571717 @qq.com).

Tiejun Wu (corresponding author) is an associate professor in Mechanical and Electronic Engineering Department, Dongguan Polytechnic, Dongguan 523808, China (email: wtj1980@126.com).

Article submitted 05 February 2018. Resubmitted 25 February and 27 February 2018. Final acceptance 25 March 2018. Final version published as submitted by the author. 